\title{
VICO DESDE UNA PERSPECTIVA PERSONAL
}

\author{
Marcel Danesi \\ (Universidad de Toronto)
}

RESUMEN: No puede subestimarse la importancia de las opiniones de Vico sobre el lenguaje para la lingüística contemporánea. Yo mismo soy prueba de ello. Insatisfecho con los modelos generativos en boga en los años '70, me dirigí hacia Vico en busca de inspiración. Aquella decisión cambió dramáticamente mi propia vida profesional y el foco de mi investigación. En este artículo discuto las razones por las que Vico fue tan importante para mí y, por extensión, para la lingüística actual. El foco actual en la metáfora como médula del lenguaje es viquiano en su perspectiva, y este artículo explica por qué.

PAlabras ClaVE: Vico, $350^{\circ}$ Aniversario, metáfora, lógica poética, lingüística, semiótica, Lakoff \& Johnson, G. Cantelli, M. Danesi.

\section{Vico from a personal perspective}

ABSTRACT: The importance of Vico's views on language to contemporary linguistics cannot be underestimated. I am proof of this. Becoming dissatisfied with generative models in vogue in the 1970s, I turned to Vico for insights. That decision changed my own professional life and research focus dramatically. This paper discusses the reasons why Vico was so important to me and, by extension, to linguistics today. The focus on metaphor as the backbone of language today is Vichian in its perspective, and this paper explains why it is so.

KEYWORDS: Vico, $350^{\text {th }}$ Anniversary, metaphor, poetic logic, linguistics, semiotics, Lakoff \& Johnson, G. Cantelli, M. Danesi.

\section{Vico da una prospettiva personale}

RiassunTo: Non dev'essere sottovalutata l'importanza delle opinioni di Vico sul linguaggio per la linguistica contemporanea. Io stesso ne sono testimone. Insoddisfatto dei modelli generativi in voga negli anni ' 70 , mi sono rivolto a Vico in cerca di ispirazione. Quella decisione ha cambiato drammaticamente la mia vita professionale e il focus della mia ricerca. In questo articolo discuto i motivi per cui Vico fu così importante per me e, per estensione, per la linguistica attuale. L'attuale focus sulla metafora come sostanza del linguaggio è prospettiva propriamente vichiana e questo articolo ne spiega il perché.

PARole ChiAVE: Vico, $350^{\circ}$ Anniversario, metafora, logica poetica, linguistica, semiotica, Lakoff \& Johnson, G. Cantelli, M. Danesi.

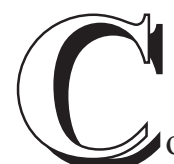

omo lingüista, descubrí la visión que tenía Vico del lenguaje cuando me sentí insatisfecho con las teorías formalistas a principios de los años '70; era

Este artículo responde a una invitación expresa por parte de la Dirección de la Revista para este volumen especial por el $350^{\circ}$ Aniversario del nacimiento de G. Vico, habiendo superado los criterios de valoración y del proceso de aceptación. 
una de ellas que el generativismo era el modelo principal en la lingüística, donde el estudio de las propiedades supuestamente universales de la gramática constituía la tendencia dominante. Esta perspectiva universalista-innatista se basaba en la observación de que, cuando juntamos palabras para expresar un pensamiento o transmitir una información, la combinación no es aleatoria, sino que se basa en una serie de reglas, y por lo tanto el significado de una estructura combinatoria no se debe computar como la suma del significado de sus partes, sino que se debe computar separadamente, desde la gramática. De esta premisa surgió un énfasis en la sintaxis abstracta como esencia del lenguaje. Gran parte de la lingüística pasó a dedicarse al estudio de las unidades y las formas del lenguaje de manera aislada y de cómo sus combinaciones, como si de un algoritmo computacional se tratase, forman oraciones. Así pues, el significado se vio desplazado del acto de combinación y relegado a un plano distinto del lenguaje. Desde este punto de vista, las oraciones se nos presentan como estructuras determinadas por principios regidores abstractos y subconscientes, de la misma forma que un arquitecto combina distintas formas arquitectónicas para diseñar un edificio. Esta perspectiva continúa informando gran parte del formalismo actual.

Por aquella época yo daba clases de italiano a estudiantes anglófonos en la Universidad de Toronto, y me di cuenta de que la instrucción gramatical es, por su cuenta, prácticamente inútil a la hora de impartir una verdadera competencia lingüística. En 1980 me hice con el ahora clásico de George Lakoff y Mark Johnson, Metaphors We Live By, ${ }^{1}$ un libro que trajo consigo un cambio de paradigma en la investigación lingüística. Su tesis principal es que la metáfora no es un elemento figurativo meramente decorativo, un uso excepcional del lenguaje, sino la base misma de los sistemas semánticos. El argumento me resultó tan claro y convincente que poco a poco me llevó ante las puertas de la monumental obra de Vico, Scienza nuova, que hasta entonces había ignorado. Al principio el trabajo de Vico me pareció tener poca o ninguna relevancia para la enseñanza de idiomas en el aula. Sin embargo, acabé por darme cuenta de que la metáfora es un eje central del lenguaje en todas sus dimensiones, ya sea en lo gramático, en lo semántico, o en lo conceptual. Inspirándome en Vico, en 1986 propuse la noción de fluidez conceptual, un término que simplemente trataba de alertar a otros profesores de idiomas sobre la relevancia del argumento principal de Vico: que la competencia lingüística reside en la capacidad de utilizar apropiadamente conceptos metafóricos en el discurso. ${ }^{2}$ El término trataba de resaltar el hecho de que los estudiantes de idiomas tienen poco o ningún acceso a los conceptos metafóricos que forman la lengua que aprenden, ya que tradicionalmente se había implantado en la

1. Lakoff, G. \& Johnson, M., Metaphors We Live By, Chicago University Press, Chicago, 1980. (Publicado en castellano como Metáforas de la vida cotidiana, trad. de C. González Marín, Cátedra, Madrid, 1986).

2. Véase un resumen en: DANESI, M., Conceptual Fluency Theory and the Teaching of Foreign Languages, Nova Science Publishers, Nueva York, 2017. 
pedagogía la idea de que el significado literal era la base de la semántica.

Pronto me di cuenta de que la perspectiva de Vico de la metáfora como reflejo de la creatividad discursiva, así como del origen del lenguaje mismo, era innegable. Esto me llevó a escribir varios libros sobre la importancia de Vico para el estudio de los orígenes del lenguaje. ${ }^{3}$ A partir de ahí todo cambió en mi carrera como lingüista. Es más, la noción de Vico de lógica poética estableció la base para que pudiese explorar sistemas de signos, la creatividad, y otros aspectos de la creación del significado desde un ángulo científico mucho más productivo.

Leer a Vico diversificó y enriqueció mi análisis del lenguaje. Me llevó, por ejemplo, a considerar el trabajo de Wilhelm von Humboldt sobre la relación entre el lenguaje y la cognición, ${ }^{4}$ donde sostuvo que a pesar de que las lenguas pueden tener reglas similares en la construcción de sus gramáticas, estas tan solo arañan la superficie de lo que la facultad del lenguaje realmente es. Para él, el lenguaje es una herramienta para tallar el mundo en función de las necesidades de quien lo utiliza. Bajo la superficie, las reglas de una lengua cuentan una historia bien distinta a la de la lógica de selección y combinación de formas. Estas reglas son un reflejo de lo que Humboldt llama innere Sprachform ("forma lingüística interna"), la cual codifica la perspectiva particular de aquellos que hablan una lengua, y que él describe de esta forma:

«El hecho central de una lengua es que sus hablantes pueden hacer un uso infinito de los recursos finitos que les proporciona. A pesar de que la capacidad para el lenguaje es universal, la individualidad del lenguaje es una propiedad de las gentes que la hablan. Toda lengua tiene su innere Sprachform, o estructura interna, que determina su forma externa y es reflejo de la mente de sus hablantes. Es por ello que la lengua y el pensamiento de un pueblo son inseparables». ${ }^{5}$

En los años '90 quedé cautivado por el trabajo de lingüistas viquianos como Gianfranco Cantelli, ${ }^{6}$ el cual me abrió los ojos a las debilidades del racionalismo en la lingüística y al papel que juega la fantasia en la conciencia humana. Recordando a Descartes, Cantelli señala el fracaso de la inteligencia artificial contemporánea a la hora de tratar de comprender la mente humana:

«Cartesio nulla poteva sapere dei nostri calcolatori elettronici e dei nostri tentativi di costruire l'intelligenza artificiale, ma per concepire

3. Danesi, M., Vico, Metaphor, and the Origin of Language, Indiana University Press, Bloomington, 1993. ID., Poetic Logic: The Role of Metaphor in Thought, Language, and Culture, Atwood Press, Madison, 2004.

4. Humboldt, W. von, On Language: The Diversity of Human Language-Structure and Its Influence on the Mental Development of Mankind, trad. de P. Heath, Cambridge University Press, Cambridge, 1836.

5. HuMBoldt, W. von, op. cit., ed. 1988, p. 43.

6. CANTElli, G., La parola come similitudine dell'uomo, Morano Editore, Nápoles, 1992. 
la possibilità di una macchina capace di simulare perfettamente qualsiasi azione o discorso intelligente dell'uomo, non gli era affatto necessaria una conoscenza di questo genere, bastava che richiamasse alla mente quanto i suoi maestri gesuiti al Collegio di La Flèche gli avevano insegnato». ${ }^{7}$

La imagen que el paradigma cartesiano ha creado para la lingüística formalista es la de la mente como autómata -una máquina abstracta que continuamente manufactura sartas de símbolos bien formados-. Sin embargo, si fuese tan sencillo, sería tarea fácil impartir idiomas a los alumnos. Pero los alumnos no son máquinas, y el lenguaje requiere de subjetividad y creatividad, y no tan solo de generatividad gramática.

La lógica poética de Vico es, a mi entender, la clave para entender el origen filogenético del lenguaje. A finales del siglo XVIII, la filología empezó a comparar grupos de lenguas emparentadas y a realizar hipótesis sobre la posibilidad de un ancestro común o protolengua. Hacia el diecinueve, los filólogos habían ya reunido suficientes pruebas de la existencia de una lengua remota común de la cual habrían evolucionado gran parte de las lenguas de Eurasia. Se llegó a la hipótesis de que esta lengua, el denominado idioma protoindoeuropeo (pIE), se hablaba mucho antes de las primeras civilizaciones, habiéndose dividido en diferentes lenguas en el curso de un milenio. Lo que motivaba estos esfuerzos era la posibilidad, en un futuro, de ensamblar esta Ursprache ("lengua primitiva") a través de la reconstrucción de otras varias protolenguas. Cuando me puse a examinar las maneras de abordar esta cuestión, me di cuenta de que la lógica poética de Vico nos proporciona la mejor pista de cómo sucedió todo. En la Scienza nuova, Vico reconstruye un escenario verdaderamente fascinante. Según Vico, las primeras palabras debieron designar sus referentes de una forma directa y no arbitraria. Esta forma primitiva de cognición era poética (metafórica e imaginativa), y habría dejado una impronta residual en las lenguas modernas. Para Vico, el flujo de la filogénesis lingüística va de lo poético a lo racional, de lo concreto a lo abstracto, de lo icónico a lo simbólico, y de lo creativo a lo mimético. En este escenario, la fuerza creativa es la fantasia, y la fuerza de enlace la metáfora (la habilidad de conectar lo que la imaginación ha generado). En mi opinión, cualquier discusión sobre el origen del lenguaje no puede ignorar esta sencilla, y sin embargo profundamente perspicaz, reconstrucción del lenguaje y del pensamiento primitivo.

7. CANTELli, G., op. cit., p. 213. [Citado originalmente en italiano por el Autor. «Descartes no podía saber de nuestras calculadoras electrónicas ni de nuestros intentos por construir inteligencia artificial, pero, para concebir la posibilidad de una máquina capaz de imitar perfectamente cualquier acción o discurso inteligente del hombre, no le había sido necesario un conocimiento de este tenor, pues bastaba con que rememorase mentalmente cuanto sus maestros jesuitas del Colegio de La Flèche le habían enseñado». N.E.] 
En conclusión, mi descubrimiento de Vico en los años '70 y la incorporación de sus ideas a mi propio trabajo me llevó por un viaje fascinante a los orígenes del lenguaje, los sistemas de signos, y la mente humana misma. Me hizo un mejor estudioso y desde luego un mejor profesor. Ojalá haya inspirado a mis alumnos a leer la Scienza nuova, ya que su discusión de la naturaleza humana sigue siendo tan significativa y perspicaz como siempre, quizás aún más en la era digital. Vico hizo de la fantasia el eje central de su "ciencia de la humanidad", la cual veía como la facultad que generaba el pensamiento, el lenguaje y la cultura. Vico buscó un acceso a su funcionamiento, no por el método cartesiano de observación y análisis, sino a través de un análisis de artefactos simbólicos -especialmente los primeros mitos y palabras de la humanidad- nacidos de la imaginación primitiva. Aprendí de Vico que los humanos primero "sienten", después "imaginan" lo que sienten, y por último intentan desarrollar ideas específicas de sus imaginaciones a través de la metáfora.

Vico nos presenta una perspectiva optimista. La gente y las culturas evolucionan y se convierten en entidades "humanísticas" -ya sea por "recurso" a una era anterior, o por reinventarse a través de la fantasia-. Al dar mayor valor a la poesía, el arte, y a otras actividades humanísticas, Vico afirma que siempre recuperaremos nuestra humanidad ética, volviéndonos más conscientes de la humanidad común que hay en todos nosotros.

[Traducción del inglés por Javier Moreno Zacarés]

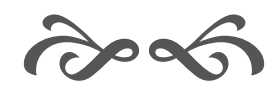


<smiles>[As]</smiles> 